\title{
Campbell diagram analysis of open cracked rotor
}

\author{
R. Tamrakara ${ }^{a^{*}}$ and N. D. Mittal ${ }^{\mathrm{b}}$
}

${ }^{a}$ PhD Scholar, Department of Mechanical Engineering, MANIT Bhopal, India

${ }^{b}$ Professor, Department of Mechanical Engineering, MANIT Bhopal, India

\begin{tabular}{l}
\hline A R T I C L E I N F O \\
\hline Article history: \\
Received 6 September, 2015 \\
Accepted 12 January 2016 \\
Available online \\
14 January 2016 \\
\hline Keywords: \\
Campbell diagram \\
Stiffness \\
Engine order line
\end{tabular}

\section{A B S T R A C T}

\begin{abstract}
This paper outlines the vibrational response of a cracked rotor in static and rotating condition through Campbell diagram. An open crack in the rotor changes its stiffness. The effect of which is seen on the natural frequency of the system. The natural frequency of the cracked rotor increases in comparison to un-cracked rotor. Experimental and simulation work is performed in the static condition to study the natural frequency of the rotor. Campbell diagram is generated through Simulation in ANSYS to study the critical speed variation at first (I) and second (II) Engine order (EO) line for cracked and un-cracked rotor.
\end{abstract}

(C) 2016 Growing Science Ltd. All rights reserved.

\section{Introduction}

Crack in the rotor has been major area among researchers during the past few decades as the number of cases of failure have been increased due to cracks in the rotor. Many researchers have worked and provided theoretical works to study the dynamics of cracked rotor. However, in actual the real working conditions may vary as there are many factors, which influence the working of rotor. Hence, experimental work is necessary to be accomplished to study the vibration response of the cracked rotor. The response of cracked rotor is slightly different from un-cracked rotor which can be used to avoid the critical response of the system and hence to avoid the breakdown of the rotor.

Fundamental modes of cracked and un-cracked shaft have deviation which can be used to identify the presence and position of the crack. Furthermore, the crack size can be predicted via variation in corresponding natural frequency (Tsai \& Wang, 1996). The eigen-frequency of shaft with two open crack is much more affected by the larger crack i.e. the eigen-frequencies reduces with crack depth. In rotors with low slenderness ratio, the change in eigen-frequencies due to crack can be seen appreciably (Sekhar, 1999; Dong \& Chen, 2011). A crack in the rotor is supposed to be the cause of coupling between lateral and longitudinal vibration. Providing axial impulses to the cracked rotor, the bending

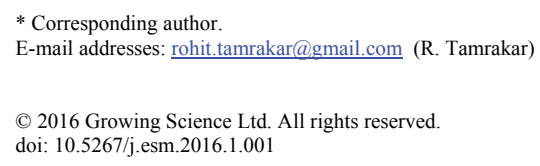


natural frequency and side bands are likely to appear around the excitation frequency and its harmonics in the spectral analysis (Darpe et al. 2002). The response of the rotor having two breathing crack changes with the orientation of the cracks, due to the change in the breathing behaviour and ultimately the stiffness of the rotor. This change is significantly observed at low speed (Darpe et al., 2002). A cracked beam has separation of natural frequencies due to coupled motion in two orthogonal directions in presence of a crack. The separation is more when the crack is at anti-nodal point of the mode shape. The least square identification technique in conjunction with the bisection root searching method can be used to determine the crack depth by defining an error function in terms of the theoretical and estimated flexibility coefficients (Dharmaraju et al., 2005). Experimental nonlinear dynamic analysis of rotor with one transverse fatigue crack shows that the crack reduces first order critical speed and high order harmonic components starts appearing. The vibration amplitude increases when crack direction coincides with additional eccentricity whereas for opposite direction amplitude first decreases and then increases (Zhou et al., 2005). Campbell diagram is suitable for analysis of the travelling waves in the rotating elastic continuum. The intersection point between the $1 \mathrm{X}$ synchronous speed line and the modes shape line in the Campbell diagram is not straightforward with low damping symmetric rotors and with non symmetric high damped rotors the intersection do not give any forbidden speed range (Kirillow, 2009; Dumitru et al., 2009). The detection of the crack is easier during the start-up and the transient response remain unaffected in presence of small crack and hence short time Fourier transform (STFT) response can be proved to identify small cracks (Silani et al., 2013). A cracked rotor can be assumed to behave as a beam of circular cross section with rotating coordinate system attached to it. Due to this, rotor bending can be decomposed in two perpendicular directions and the crack seems horizontal in one direction and vertical in another direction. Further applying Galerkin method and Hamilton principle to the model can be used to understand the dynamic behaviour of the cracked rotors for early detection of cracks (Ebrahimi et al., 2014). One dimensional beam finite element model can be used to model the rotor for rotor dynamic analysis (HadiJalali et al., 2014). Campbell diagram, dynamic bearing forces due to an unbalance load and Critical speed maps are significantly important in rotor dynamic analysis specially to analyze the coupling of rotating and non-rotating parts with rotors (Wagner \& Helfrich, 2013). In this paper vibrational response of a cracked rotor in static and rotating condition is investigated through Campbell diagram. Also, the natural frequency of the rotor is studied both experimentally and numerically.

\section{Equation of motion}

The schematic diagram of the rotor system with open crack is shown in Fig. 1.
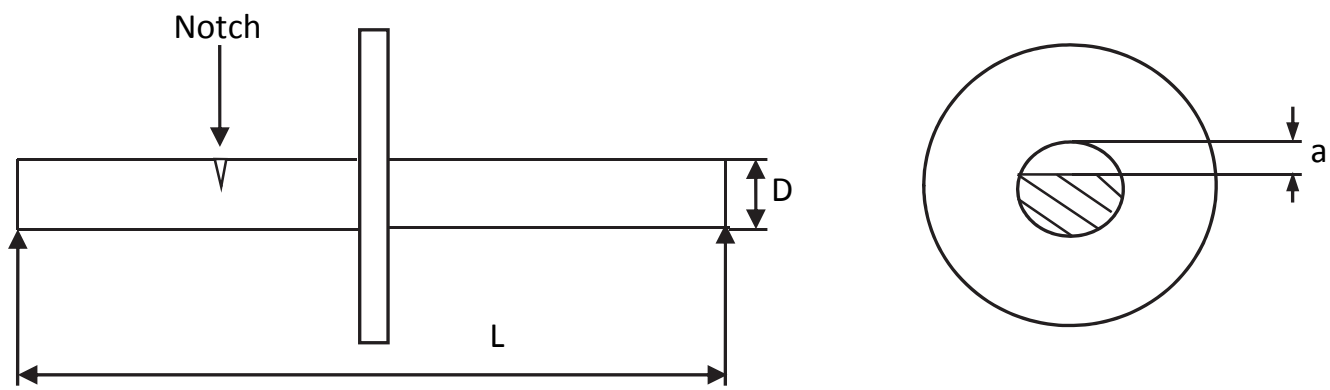

Fig. 1. Rotor system with open crack

The equation of motion of the rotor is given by

$$
[\mathrm{M}] \ddot{q}+[\mathrm{D}] \dot{q}+[\mathrm{K}] \mathrm{q}=\mathrm{Q}
$$

where, 
$[\mathrm{M}]$ is the mass matrix

[D] isdamping matrix

$[\mathrm{K}]$ is stiffness matrix

The details of these three matrices of Eq. (1) can be found in Nelson and McVaugh (1976). Here the notch is considered as open crack. Open cracks lead to linear system, whereas closing or breathing crack lead to non-linear system. The presence of transverse open crack induces a change in the behaviour of local flexibility due to strain energy concentration in the vicinity of the crack. The local flexibility matrix for cracked rotor which is obtained by adding the local flexibility due to the crack to the local flexibility of the un-cracked rotor and is given by Papadopoulos and Dimarogonas (1987).

$$
C=\frac{1}{F_{o}}\left[\begin{array}{cccccc}
c_{11} R & 0 & 0 & c_{14} & c_{15} & 0 \\
0 & c_{22} R & 0 & 0 & 0 & c_{26} \\
0 & 0 & c_{33} R & 0 & 0 & c_{36} \\
c_{41} & 0 & 0 & c_{44} / R & c_{45} / R & 0 \\
c_{51} & 0 & 0 & c_{54} / R & c_{55} / R & 0 \\
0 & c_{62} & c_{63} & 0 & 0 & c_{66} / R
\end{array}\right]
$$

where, $c_{i j}(i, j=1,2, \ldots . ., 6)$ are the dimensionless compliance coefficients, details can be found in (Papadopoulos and Dimarogonas, 1987) and $F_{o}=\frac{\pi E R^{2}}{1-v^{2}}, \mathrm{R}=\mathrm{D} / 2$ and $v=0.3$.

\section{Experiment setup}

The experiment set up consist of TGP steel notched shaft carrying an Aluminium disc (Fig. 2). The shaft is fixed at both ends.

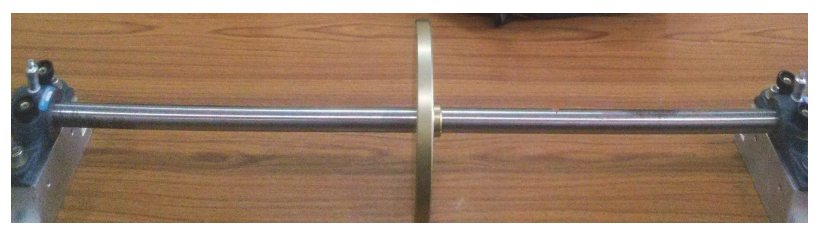

Fig. 2. TGP steel shaft with Aluminium disc



Fig. 3. Dynapulse hammer

Modal analysis is performed by impact hammer test. DytranDynapulse hammer (Fig. 3) is used for excitation of the set up. The impulse generated was read through Vibpilot (four channel analyzer, Fig. 4). The signal through Vibpilot is processed and displayed on screen through Smart Office (SO) analyzer. Single axial accelerometer shown in Fig. 5 is used for measuring the transverse vibration response of the system. Fig. 6 shows the basic schematic diagram of the experimental set up. Table 1 . Gives the specification of the experimental set up.

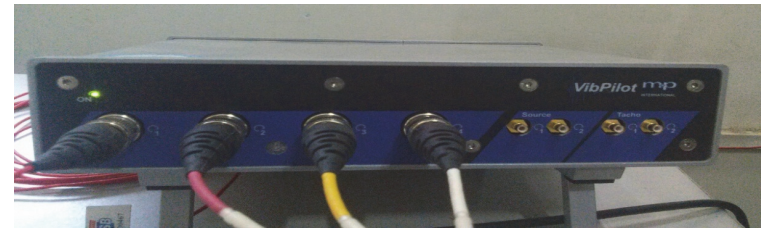

Fig. 4. Vibpilot (4 channel analyzer)

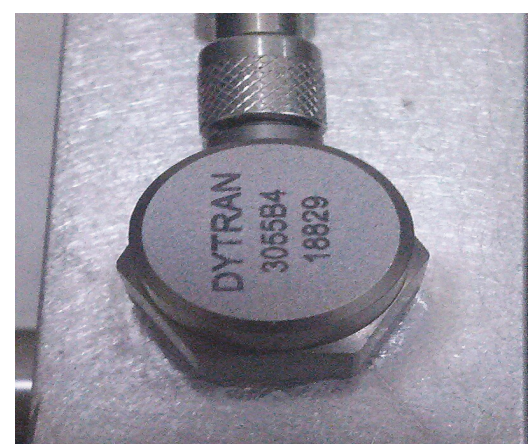

Fig. 5. Single Axial accelerometer 


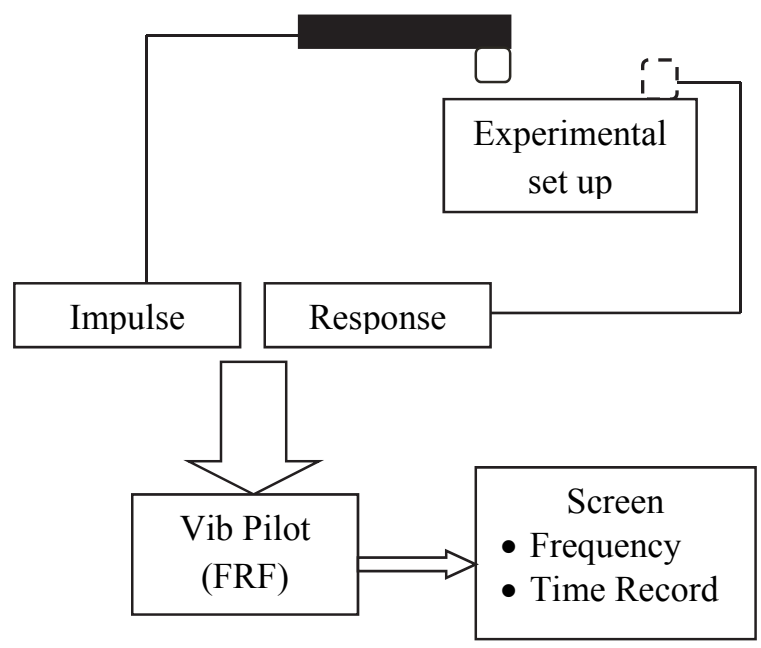

Fig. 6. Schematic diagram of experimental set up

Table 1. Specification of set up

$\begin{array}{cc}\text { Diameter of Shaft (D) } & 0.75 \text { inch } \\ \text { Length of Shaft (L) } & 33 \text { inch } \\ \text { Disc Diameter (d) } & 6 \text { inch } \\ \text { Notch depth (a) } & 0.115 \text { inch } \\ \text { Notch width (w) } & 0.375 \text { inch }\end{array}$

\section{Result and discussion}

Experimental modal analysis of the shaft with open crack carrying Aluminium rotor was carried out to study the free vibration behaviour of the rotor system. The rotor was analyzed under fixed-fixed condition. The results obtained were compared with the result through Finite Element Method (FEM) in ANSYS. Table 2 show the obtained values of natural frequency of the system for the first two modes experimentally and through FEM. Fig. 7 gives the natural frequency obtained experimentally.

Table 2. Experimental and FEM natural frequency data of the cracked rotor system

\begin{tabular}{lccc}
\hline Mode & Experimental $(\mathrm{Hz})$ & ANSYS $(\mathrm{Hz})$ & Difference (\%) \\
\hline 1 & 51 & 41.09 & 19 \\
2 & 205 & 208.95 & 1.9 \\
\hline
\end{tabular}

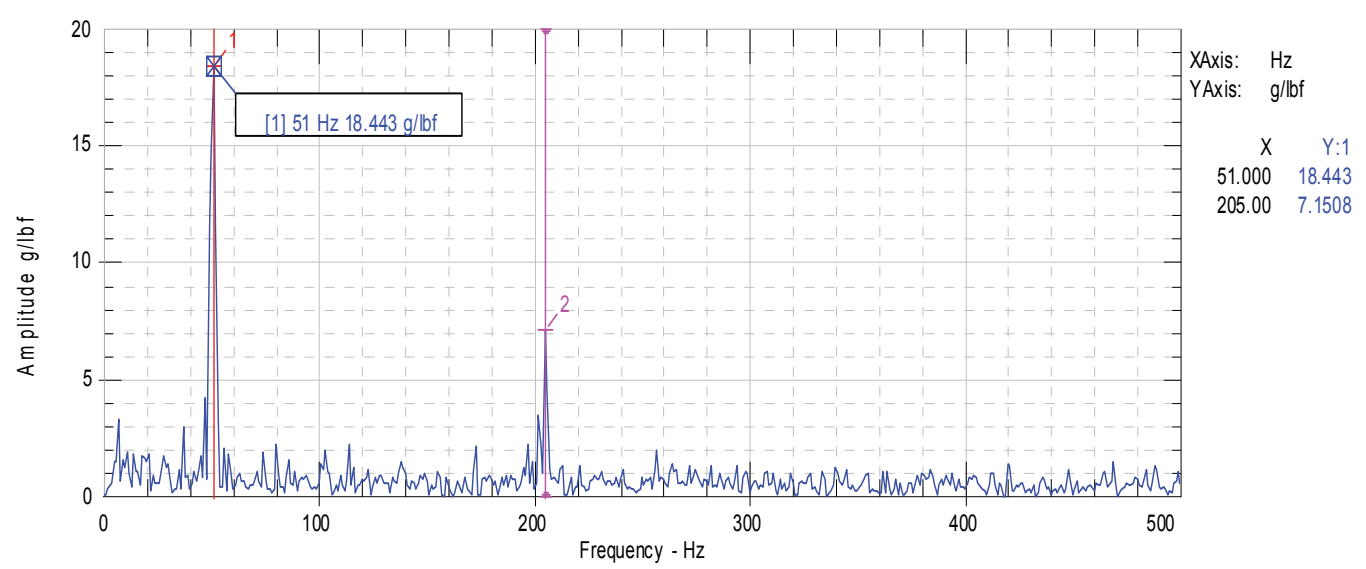

Fig. 7. Experimentally obtained natural frequency of the cracked rotor system. 
FEM analysis of cracked and un-cracked rotor system shows that the natural frequency of the cracked rotor increases slightly from that of the un-cracked rotor. The possible cause is the change in the stiffness of the cracked rotor due to the concentration of strain energy in the vicinity of the crack. Table 3 shows the natural frequency for cracked and un-cracked rotor system obtained through FEM analysis. It can be seen form Table 2 that the percentage difference for natural frequency between cracked and un-cracked rotor system increases with the modes.

Table 3. Natural frequency for cracked and un-cracked rotor system through FEM

\begin{tabular}{lccc}
\hline Mode & Natural Frequency (cracked rotor, Hz) & Natural Frequency (un-cracked rotor, Hz) & Difference (\%) \\
\hline 1 & 41.09 & 40.88 & 0.5 \\
2 & 208.95 & 207.74 & 0.4 \\
3 & 406.78 & 403.29 & 0.8 \\
\hline
\end{tabular}

The Campbell diagram gives the plot of natural frequency of the system versus the rotation speed of the shaft. Campbell diagram analysis is utilized to get the critical speed of the rotor system which can be of great importance for controlling the resonance by providing the necessary damping during the pass through of the critical speed for the rotor system. Figs. (8-9) show the Campbell diagram for cracked and un-cracked rotor, respectively for I EO line. Similarly Figs. (10-11) show the Campbell diagram for cracked and un-cracked rotor for II EO line. From comparing the critical speed in Table 4, it can be seen that the critical speed for the cracked rotor increases more than that of the un-cracked rotor for both obtained by I and II EO line. The cause of this increase in the critical speed is the increase of natural frequency of the cracked rotor than that of un-cracked rotor. It is also seen that that the whirling takes place in backward direction in most of the mode.

Table 4. Critical speed with respect to I and II EO line

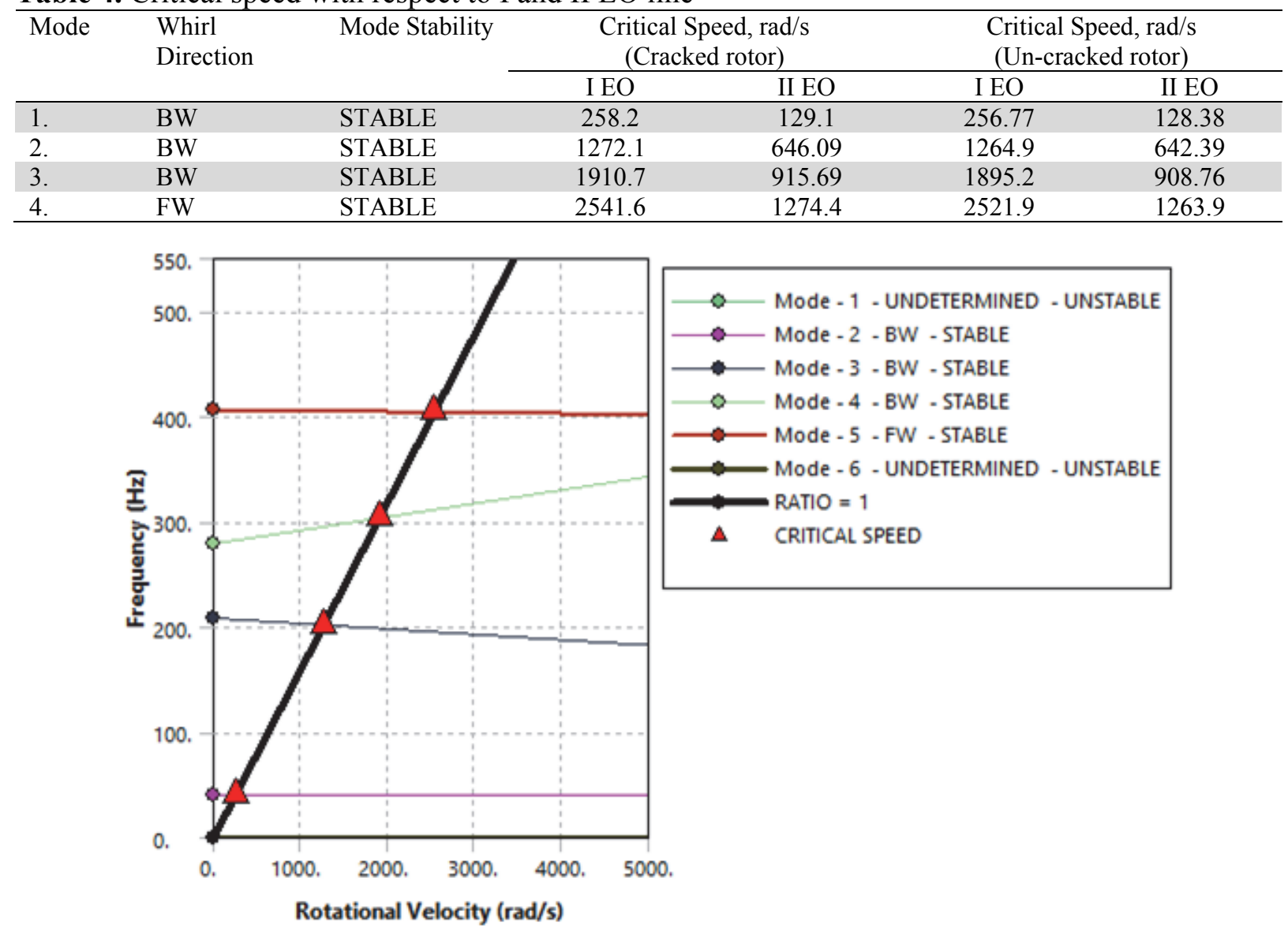

Fig. 8. Campbell diagram for cracked rotor system for I EO line 


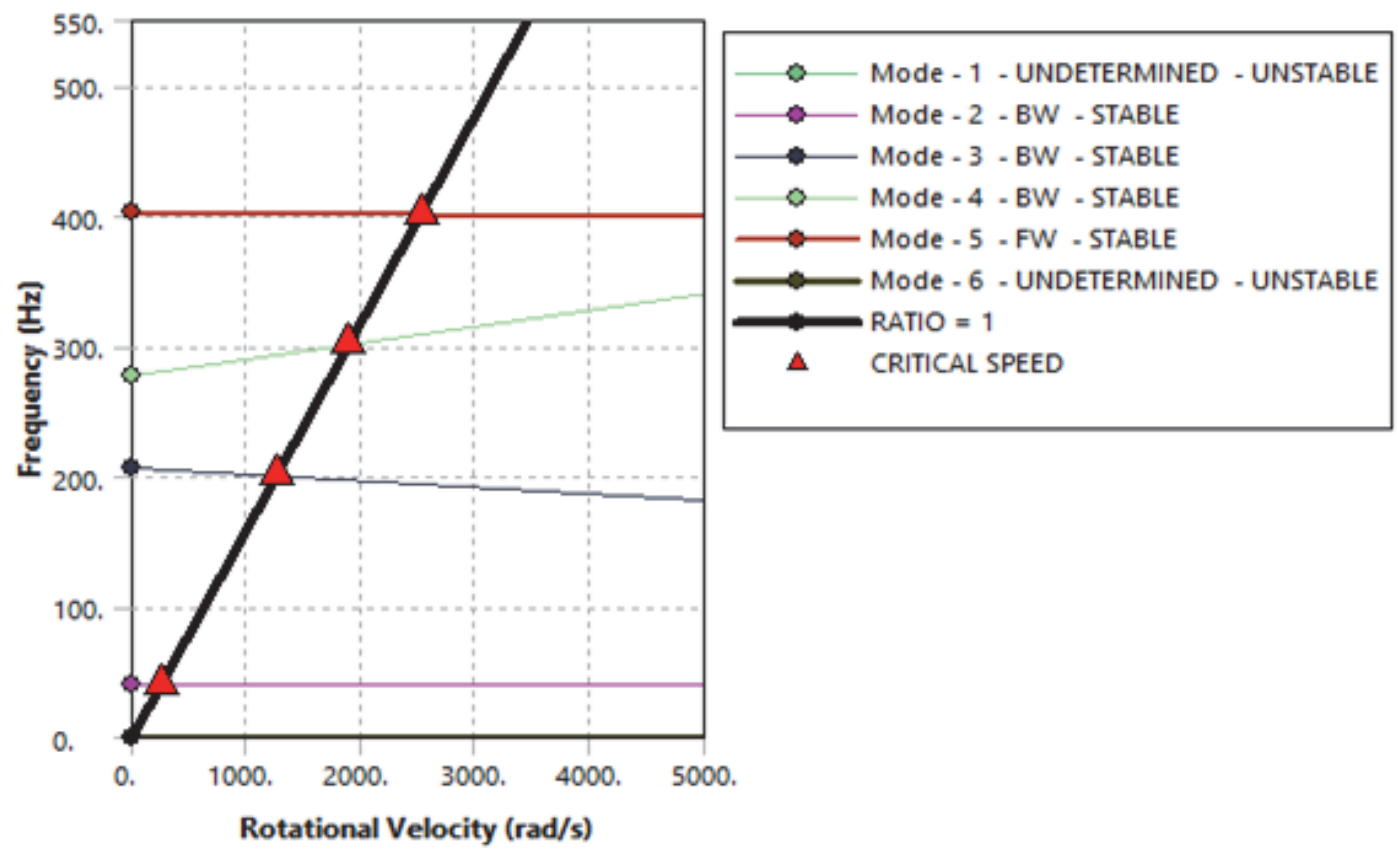

Fig. 9. Campbell diagram for un-cracked rotor system for I EO line

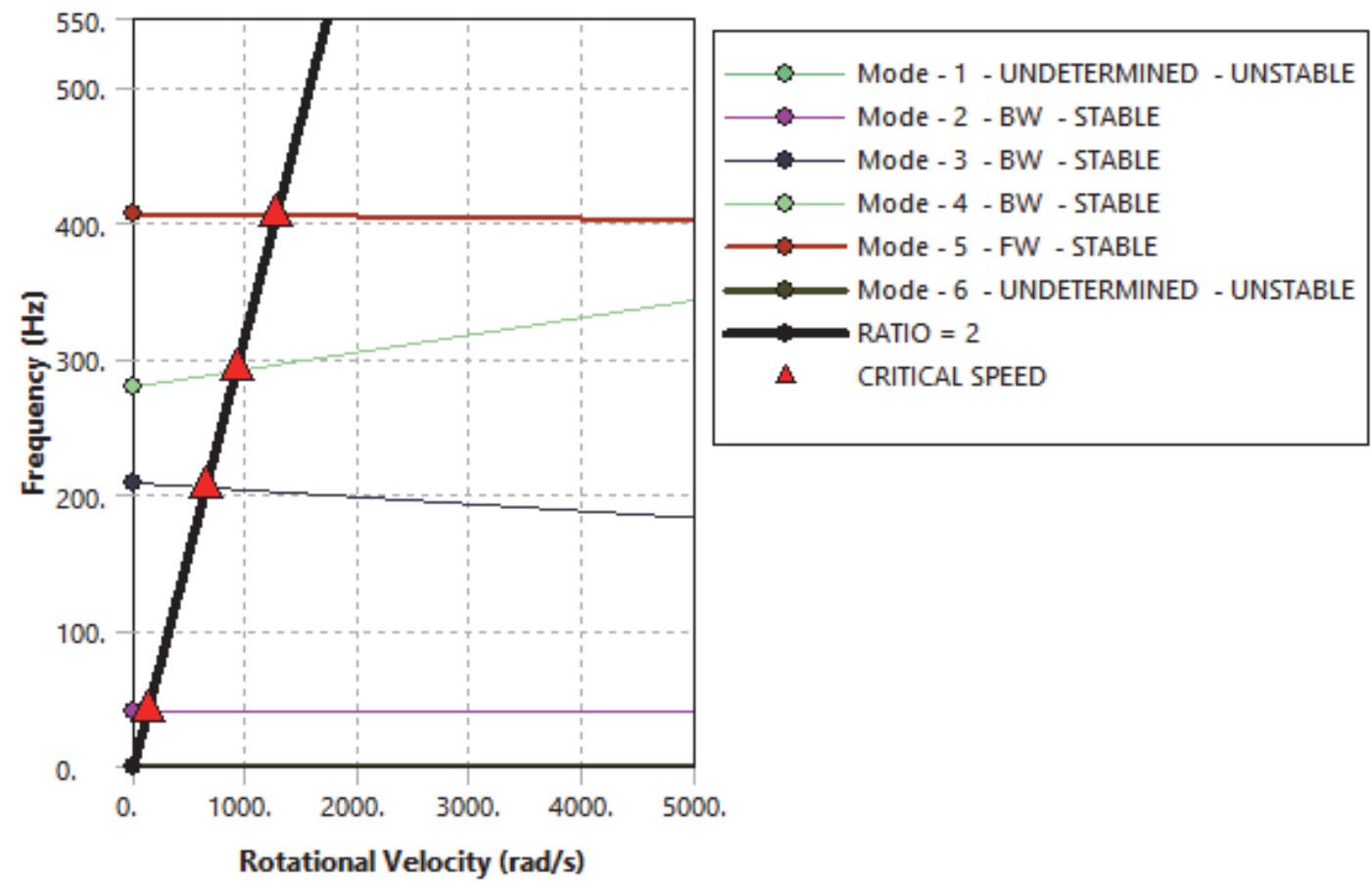

Fig. 10. Campbell diagram for cracked rotor system for II EO line 




Fig. 11. Campbell diagram for un-cracked rotor system for II EO line

\section{Conclusion}

The effect of crack on the natural frequency of the rotor system with open crack has been studied and it has been observed that the crack had a significant effect on increasing the natural frequency of the rotor system in comparison to the un-cracked rotor system. This is because of the accumulation of the strain energy in the vicinity of the crack. This effect can be utilized to study the dynamics behaviour of the rotor through Campbell diagram analysis. It gives the critical speed of the system which is likely to occur during the runtime of the rotor. Through this analysis it is seen that the critical speed of the cracked rotor increases than that of the un-cracked rotor. This can be used as a tool to see the possible presence of the crack in the rotor.

\section{References}

Darpe, A. K., Chawla, A., \& Gupta, K. (2002). Analysis of the response of a cracked Jeffcott rotor to axial excitation. Journal of Sound and Vibration, 249(3), 429-445.

Darpe, A. K., Gupta, K., \& Chawla, A. (2003). Dynamics of a two-crack rotor. Journal of Sound and Vibration, 259(3), 649-675.

Dharmaraju, N., Tiwari, R., \& Talukdar, S. (2005). Development of a novel hybrid reduction scheme for identification of an open crack model in a beam. Mechanical systems and signal processing, 19(3), 633-657.

Dong, G., \& Chen, J. (2011). Vibration analysis and crack identification of a rotor with open cracks. Japan journal of industrial and applied mathematics, 28(1), 171-182.

Dumitru, N., Secarả, E., \& Mihảlcicả, M. (2009). Study of rotor-bearing systems using campbell diagram. Proceedings of the 1st International Conference on Manufacturing Engineering, Quality and Production Systems (Volume II).

Ebrahimi, A., Heydari, M., \& Behzad, M. (2014). A continuous vibration theory for rotors with an open edge crack. Journal of Sound and Vibration, 333(15), 3522-3535.

Jalali, M. H., Ghayour, M., Ziaei-Rad, S., \& Shahriari, B. (2014). Dynamic analysis of a high speed rotor-bearing system. Measurement, 53, 1-9. 
Kirillov, O. N. (2009, June). Campbell diagrams of weakly anisotropic flexible rotors. In Proceedings of the Royal Society of London A: Mathematical, Physical and Engineering Sciences (p. rspa20090055). The Royal Society.

Nelson, H. D., \& McVaugh, J. M. (1976). The dynamics of rotor-bearing systems using finite elements. Journal of Manufacturing Science and Engineering, 98(2), 593-600.

Papadopoulos, C. A., \& Dimarogonas, A. D. (1987). Coupled longitudinal and bending vibrations of a rotating shaft with an open crack. Journal of sound and vibration, 117(1), 81-93.

Sekhar, A. S. (1999). Vibration characteristics of a cracked rotor with two open cracks. Journal of Sound and Vibration, 223(4), 497-512.

Silani, M., Ziaei-Rad, S., \& Talebi, H. (2013). Vibration analysis of rotating systems with open and breathing cracks. Applied Mathematical Modelling, 37(24), 9907-9921.

Tsai, T. C., \& Wang, Y. Z. (1996). Vibration analysis and diagnosis of a cracked shaft. Journal of Sound and Vibration, 192(3), 607-620.

Wagner, N., \& Helfrich, R. (2013). Dynamics of rotors in complex structures. NAFEMS World Congress June 9-12, 2013, Salzburg, Austria.

Zhou, T., Sun, Z., Xu, J., \& Han, W. (2005). Experimental analysis of cracked rotor. Journal of dynamic systems, measurement, and control, 127(3), 313-320. 